http://jmscr.igmpublication.org/home/

ISSN (e)-2347-176x ISSN (p) 2455-0450

crossref DOI: https://dx.doi.org/10.18535/jmscr/v7i10.115

Journal Of Medical Science And Clinical Research

IGM Publication

An official Publication of IGM Publication

\title{
Mean Platelet Volume - Predictor of Impending Diabetic Vascular Complications
}

\author{
Authors \\ E. Sumanraj ${ }^{1}$, S.Periasammy ${ }^{2}$ \\ ${ }^{1}$ Postgraduate, Department of General Medicine, RMMCH, Annamalai Nagar, Chidambaram, Tamil Nadu \\ ${ }^{2}$ Professor of Medicine, Department of General Medicine, RMMCH, Annamalai Nagar, Chidambaram, \\ Tamil Nadu, India
}

\begin{abstract}
Introduction: Diabetes Mellitus (DM) is a prothrombotic state which has influence on pathways regulating platelet function, that is represented by increased platelet reactivity. Many studies have tried to explain the pathophysiology of these hyperreactive platelets contributing to diabetic vascular complications. However, a comprehensive analysis of the relationship between Mean platelet volume and glycemic status is still lacking.

Aim: To determine the Mean Platelet volume (MPV) in diabetics compared to Non-diabetics and to find out, among the Diabetics if there is an association between MPV and micro, macrovascular complications of Diabetes and to determine the correlation of MPV with Fasting blood sugar, postprandial blood sugar, Glycosylated $\mathrm{Hb}\left(H b A_{1 c}\right)$, Body mass index and duration of Diabetes.

Materials and Method: A total of 100 patients (Study - 50; Control - 50) admitted in medicine wards of Rajah Muthiah Medical College, Annamalai Nagar, Chidambaram from September 2017 to October 2018 were studied. Our patients were on treatment with insulin or OHAs. All the patients were put through a detailed clinical evaluation. Height, weight were measured in all subjects and BMI was calculated.

Results: Diabetics had elevated MPV in comparison to non-diabetics. MPV was significantly higher among uncontrolled diabetics than patients with good glycemic control and non-diabetics. MPV showed a significant positive correlation with HbAlc, FBS and PPBS. We observed a significant difference in MPV among various grades of $\mathrm{HbAlc}$.

Conclusion: The MPV is increased in diabetics. It is a simple and inexpensive tool that can be used as a good indicator of platelet hyperactivity and predictor of upcoming vascular complications in DM.

Keywords: Diabetes Mellitus, Mean Platelet volume.
\end{abstract}

\section{Introduction}

The worldwide prevalence of DM was $2.8 \%$ in 2000 and was estimated to be $4.4 \%$ in $2030^{1}$. Type

2 diabetes comes under metabolic syndrome which leads to endothelial dysfunction, platelet hyperreactivity and increased procoagulation factors contributing significantly to the increased risk of atherosclerosis, Coronary Heart Disease, and Peripheral Arterial Disease (PAD) ${ }^{2}$. Macro and microvascular complications are a major cause of morbidity and mortality in type 2 diabetic patients, and hence there is an increasing quest to find novel biomarkers to identify and treat individuals at high risk ${ }^{3}$. 
Platelets change their shape, adhere to subendothelial surfaces of blood vessels and aggregate to form a thrombus, in response to release of proaggregatory stimuli such as thrombin, collagen generated by the endothelium ${ }^{4}$. Consequently, platelets have a significant role in the pathophysiology and development of advanced atherosclerosis in diabetes. Platelets in DM are larger and have altered signalling pathways that lead to an increased tendency to platelet activation and aggregation in response to a given stimulus ${ }^{5}$. Hence, DM has been considered to have a prothrombotic potential with effects on a wide series of pathways which regulates platelet function, the pathogenesis is represented by increased platelet reactivity ${ }^{6}$.

Alteration of platelet morphology and function has been reported in patients with DM which have important implications for assessing the functional expressions of platelets and measuring platelet size. MPV is a measure of platelet function and this is supported by evidences such as the differences in platelet volume vividly correlates with differences in dense particle content, platelet aggregation to ADP and serotonin uptake and release $^{7,8}$. Experimental evidence points to a positive association of MPV with DM, hypertension, and acute coronary syndrome ${ }^{9}$. The activated platelets change from a discoid to a spherical shape resulting in alteration of $\mathrm{PDW}^{10}$. Recent studies proposed that higher the MPV values, more the platelet activation with high proaggregatory potentials and hence, MPV can be used as a substitute marker for platelet activity in $\mathrm{DM}^{11}$.

In this study, we aimed to compare and analyse Mean platelet volume with glycemic status in type 2 diabetes patients and to identify the correlation, especially between MPV, FBS, PPBS and HbA1c values.

\section{Materials and Methods}

This analytical cross-sectional study was carried out in the Department of Medicine over a period from September 2017 to October 2018, at Rajah
Muthiah Medical college and Hospital, Annamalai Nagar, Chidabaram, Tamil Nadu, India. A total of 100 patients (Study - 50; Control - 50) admitted in medicine wards were studied. Our patients were on treatment with insulin or OHAs. All the patients were underwent a detailed clinical evaluation. Patients height and weight were measured in all subjects and BMI was calculated as weight ( $\mathrm{kg}$ ) divided by height (meters) ${ }^{2}$.

Systolic and diastolic blood pressures were measured after 5 minutes rest in a sitting position using a sphygmomanometer. Patients with blood pressure levels of $\geq 140 / 90 \mathrm{mmHg}$ or patients already on antihypertensive medications were diagnosed as having hypertension.

\section{Laboratory Methods}

Venous samples were drawn from both study and control groups after 12 hours of overnight fasting at 8:30 am for Mean platelet volume (MPV), HbA1c, FBS, PPBS. Measurement of MPV was using an automatic blood analyzer (Beckman Coulter Act5Diff CBC machine). HbA1c was measured by High performance liquid chromatography. Plasma glucose estimation was done by glucose-oxidase method in the autoanalyzer. Microalbuminuria, which is the hallmark of diabetic retinopathy was examined using spot urine albumin creatine ratio (ACR). Patients with ACR of $<20 \mathrm{mg} / \mathrm{g}$ for men and $<30 \mathrm{mg} / \mathrm{g}$ for women were categorized as microalbuminuria negative and those with $>20 \mathrm{mg} / \mathrm{g}$ and $>30 \mathrm{mg} / \mathrm{g}$ respectively as microalbuminuria positive.

Diabetic retinopathy screening was done using direct ophthalmoscope. Patients with at least 2 microaneurysms and/or retinal hemorrhage, and/or other signs of retinal injury were diagnosed as having retinopathy. After baseline evaluation, all the parameters were compared between study group (with DM) and control group (without DM). These groups were further sub grouped based on the presence or absence of complications. The MPV in each group were compared. 


\section{Statistical Analysis}

The data of laboratory examinations in this study were comprehensively collected for further statistical analysis using IBM SPSS software version 20.0. Arithmetic mean and Standard Error of Mean (SEM) were calculated and the expected value of each $\mathrm{HbA1c}$ and platelet indices was set as $95 \% \mathrm{CI}$. Then mean values of $\mathrm{p}$ in both study and control groups were compared by one-way ANOVA test to determine if a significant difference exists between these groups. The correlation between $\mathrm{HbA1c}$, FBS and platelet indices was assessed using regression analysis. Statistical significant difference was accepted at p-value $<0.05$ (Pearson correlation coefficient).

\section{Results}

The observation derived from the present study revealed that diabetics had higher MPV than nondiabetics. Among diabetics, those with glycemic status under control $\left(\mathrm{HbA}_{1 \mathrm{c}} \leq 8\right)$ showed lower MPV with mean value of $8.023 \mathrm{fL}$ than patients with poor glycemic status $\left(\mathrm{HbA}_{1 \mathrm{c}} \geq 8\right)$ with mean value of $9.521 \mathrm{fL}$. These differences were found to be statistically significant $(p=0.0001)$. Thus, we have demonstrated a significant stepwise increase in MPV from a non-diabetic group to diabetics with good glycemic control and then to uncontrolled diabetics.

Table.1: Baseline characteristics of patients involved in this study

\begin{tabular}{|c|c|c|c|}
\hline Variables & $\begin{array}{c}\text { Study group } \\
(\mathbf{n}=\mathbf{5 0})\end{array}$ & $\begin{array}{c}\text { Control group } \\
(\mathbf{n}=\mathbf{5 0})\end{array}$ & $P$ value \\
\hline Age (Years) & 54.6 & 48054 & 0.0149 \\
\hline Male & 32 & 30 & \multirow{2}{*}{0.143} \\
\hline Female & 18 & 20 & \\
\hline BMI & 27.80 & 28.12 & 0.6733 \\
\hline FBS & 156.06 & 93.88 & 0.0001 \\
\hline PPBS & 231.72 & 124.26 & 0.0001 \\
\hline MPV & 9.012 & 8.52 & 0.027 \\
\hline \multicolumn{4}{|l|}{ Hypertension } \\
\hline Present & 13 & 3 & \multirow{2}{*}{ - } \\
\hline Absent & 37 & 47 & \\
\hline \multicolumn{4}{|l|}{ Proteinuria } \\
\hline Present & 21 & 4 & \multirow{2}{*}{-} \\
\hline Absent & 29 & 46 & \\
\hline \multicolumn{4}{|l|}{ Retinopathy } \\
\hline Present & 19 & 0 & \multirow[b]{2}{*}{ - } \\
\hline Absent & 31 & 50 & \\
\hline
\end{tabular}

Table.2: Comparison of Mean platelet volume among variables

\begin{tabular}{|c|c|c|}
\hline Variables & MPV & P value \\
\hline \multicolumn{3}{|l|}{ Gender } \\
\hline Male & 8.811 & \multirow{2}{*}{0.6137} \\
\hline Female & 8.695 & \\
\hline \multicolumn{3}{|l|}{ BMI } \\
\hline Normal BMI & 8.635 & \multirow{2}{*}{0.4837} \\
\hline Overweight/ Obese & 8.818 & \\
\hline \multicolumn{3}{|l|}{ Hypertension } \\
\hline With hypertension & 9.79 & \multirow{2}{*}{0.0001} \\
\hline Without hypertension & 8.495 & \\
\hline \multicolumn{3}{|l|}{ Proteinuria } \\
\hline With proteinuria & 9.908 & \multirow{2}{*}{0.0001} \\
\hline Without proteinuria & 8.386 & \\
\hline \multicolumn{3}{|l|}{ Retinopathy } \\
\hline With retinopathy & 10.195 & \multirow{2}{*}{0.0001} \\
\hline Without retinopathy & 8.432 & \\
\hline \multicolumn{3}{|l|}{$\mathrm{HbA}_{1 \mathrm{c}}$} \\
\hline$\leq 8$ & 8.023 & \multirow{2}{*}{0.0001} \\
\hline$\geq 8$ & 9.521 & \\
\hline
\end{tabular}


Table 3: Correlation analysis

\begin{tabular}{|l|c|c|}
\hline \multirow{2}{*}{ Parameters } & \multicolumn{2}{|c|}{ Mean platelet volume } \\
\cline { 2 - 3 } & R & P value \\
\hline FBS & 0.58 & 0.0001 \\
\hline PPBS & 0.69 & 0.0001 \\
\hline Duration of diabetes & 0.26 & 0.0115 \\
\hline $\mathrm{HbA}_{1 \mathrm{c}}$ & 0.71 & 0.0001 \\
\hline
\end{tabular}

Figure.1: Scatter plots representation of correlation between a) FBS and MPV b) PPBS and MPV c) Duration of diabetes and MPV d) $\mathrm{HbA}_{1 \mathrm{c}}$ and MPV.

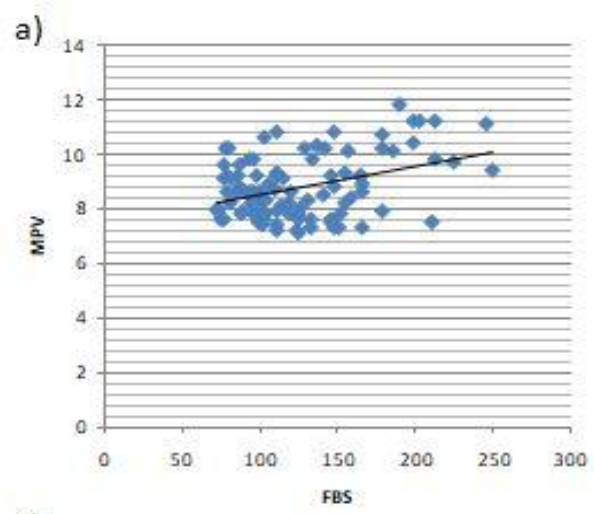

c)

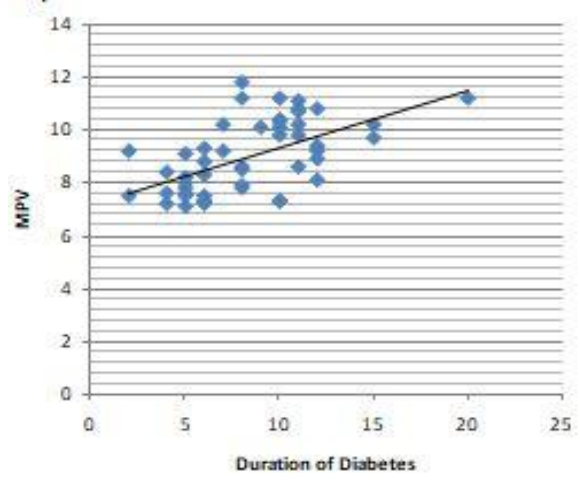

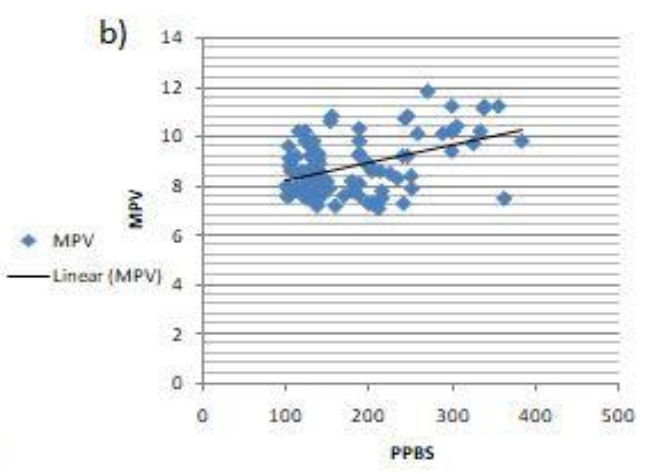

d)

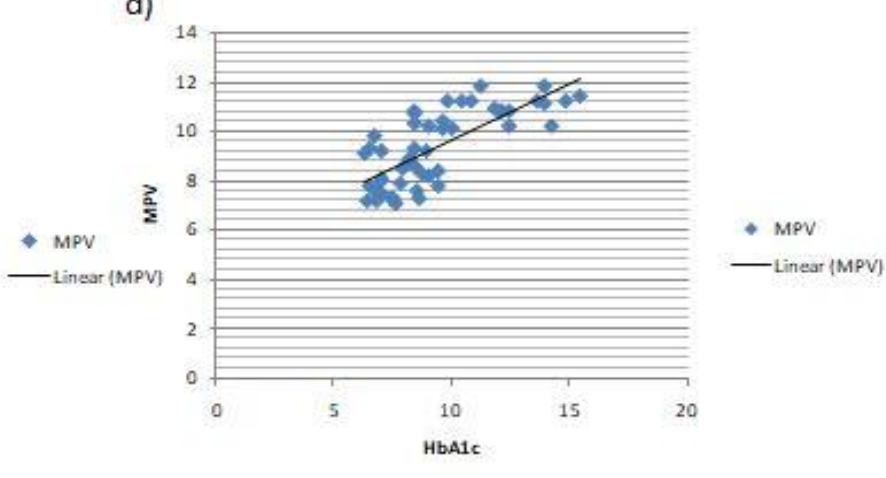

In table-3, there was a significant positive correlation found between FBS and MPV $(\mathrm{p}=0.0001)$. Similarly significant positive correlation was observed between PPBS, duration of diabetes with MPV ( $\mathrm{p}=0.0001)$. A strong positive correlation was found between $\mathrm{HbA}_{1 \mathrm{c}}$ value and MPV ( $\mathrm{p}=0.0001)$.

\section{Discussion}

Many hypotheses has been put forth in explaining the pathophysiology associated with diabetes and vascular complications: endothelial dysfunction, inflammatory state and modified platelet morphology and dysfunction ${ }^{12}$. Prothrombic state in diabetes is contributed by platelet hyperreactivity, hence causing hypercoagulability, impaired fibrinolysis and endothelial dysfunction.
Many clinical studies by Demirtunc R et al., have confirmed to have correlation between these hyperactive platelets and thrombotic events occurring in diabetic complications ${ }^{13}$.

Type 2 diabetes is associated with metabolic abnormalities like hyperglycaemia, insulin resistance and systemic abnormalities like oxidative stress and inflammation.

Winocour PD et al., proposed that hyperglycaemia increases platelet reactivity by increasing nonenzymatic glycation of proteins on the platelet surface, and also by the osmotic effect of glucose $^{14}$. Such glycation decreases membrane fluidity and increases the activation of platelets. Insulin is a natural antagonist of platelet hyperactivity. Insulin counteracts with epinephrine, collagen and platelet-activating 
factor (PAF). Both insulin resistance and insulin deficiency increase platelet reactivity ${ }^{15}$. Kakouros $\mathrm{N}$ et al., suggested that Insulin directly binds to a functional Insulin Receptor present on the surface of human platelets and thus controls the platelet function ${ }^{5}$.

In diabetes due to persistent hyperglycemia protein kinase $\mathrm{C}$ gets activated which results in platelet hyperreactivity and leads to various vascular complications ${ }^{5}$. Drugs improving insulin sensitivity and preserving pancreatic cell function, decrease activation of platelet, thereby reducing incidence of vascular complications in diabetes. Furthermore, oxidative stress and inflammation in diabetes results in endothelial dysfunction which leads to decreased synthesis of Nitric Oxide (NO), promotes platelets activation and attenuates platelet reactivity ${ }^{16}$.

MPV is an indicator of the activity and mean size of platelets ${ }^{17}$. Larger platelets are younger, hyperreactive and they have greater aggregation in comparison with smaller platelets. Larger platelets contain denser granules and secrete more serotonin and $\beta$-thromboglobulin, TXA2 producing a procoagulant effect which leads to thrombotic vascular complications ${ }^{18}$. This suggests the association between the platelet size and diabetic vascular complications, thus indicating alterations in MPV indicate the state of thrombogenesis ${ }^{19}$.

We could clearly see from the present study results that MPV was reasnoably elevated $(\mathrm{p}=0.0001)$ in uncontrolled Diabetics as compared to diabetics with good glycemic control and nondiabetic controls which correlates with the results of Kodiatte TA et al., ( $\mathrm{p}=0.003)$. Demirtunc $\mathrm{R}$ et al., $(\mathrm{p}=0.002)$, Hekimsoy $\mathrm{Z}$ et al., $(\mathrm{p}<0.0001)$, Jindal $S$ et al., $(p<0.05)$ but contradicts the results of Unübol M et al., $(\mathrm{p}=0.64)^{14,19}$.

The increase in MPV in uncontrolled Diabetics could be attributed to the following hypothetical theories. Glucose is the major source of energy for platelets. Increased utilization of glucose by platelets in DM due to chronic hyperglycemia results in synthesis of glycogen, play a role in increased MPV. Calverley DC and Thienelt CD conducted electron microscopic study of platelets which supported this by, revealing the presence of glycogen inside platelets in diabetic patients. Studies also suggest that some glucose metabolites accumulate in platelets, which leads to osmotic swelling and increase in MPV in high glycaemic patients.

Although, there are several measurements to show the platelet activity like platelet aggregometry, surface p-selectin, activated glycoprotein II b/III a, platelet function analyser-100, serum thromboxane B2 and urinary 11-dehydrate thromboxane B2, almost all of these measurements are time consuming, expensive or they require special training.

\section{Limitation}

There are few limitations in the current study such as small sample size and patients were not categorised according to diabetic complications. Hence, further multicentric research with larger sample size and qualitative platelet function analysis may provide a future strategy to prevent thromboembolic events in DM.

\section{Conclusion}

From the present results, we conclude that MPV is increased in diabetics. They are simple and costeffective tools that can be used as a good indicator of platelet activation and an independent predictor of impending vascular complications in DM. Moreover, results of the present study strongly recommend that to delay the onset or progression of vascular complications and to limit platelet activation, achieving a good glycemic control in diabetic patients is mandatory. Future research with greater sample size is needed to classify these relations in terms of the pathogenesis.

\section{References}

1. Wild SH, Roglic G, Green A, Sicree R, King H. Global prevalence of diabetes: estimates for the year 2000 and projections 
for 2030. Diabetes Care. 2004;27 (10):2569.

2. Colwell JA, Nesto RW. The platelet in diabetes. Focus on prevention of ischemic events. Diabetes Care. 2003;26(7):218188.

3. Barutta F, Bruno G, Matullo G, Chaturvedi N, Grimaldi S, Schalkwijk C, et al. MicroRNA-126 and micro/macrovascular complications of type 1 diabetes in the EURODIAB prospective complications study. Acta Diabetol. 2017;54(2):133-39.

4. Mitchell RN. Hemodynamic disorders, thromboembolic disease and shock. In: Kumar V, Abbas AK, Fausto N, Aster JC, editors. Robbins and Cotran pathologic basis of disease. 8th ed. New Delhi. Elsevier. 2010. pp. 111-34.

5. Kakouros N, Rade JJ, Kourliouros A, Resar JR. Platelet function in patients with diabetes mellitus: from a theoretical to a practical perspective. Int $\mathrm{J}$ Endocrinol. 2011;2011:742719.

6. Pomero F, Di Minno MN, Fenoglio L, Gianni M, Ageno W, Dentali F. Is diabetes a hypercoagulable state? a critical appraisal. Acta Diabetol. 2015;52(6):1007-16.

7. Handin RI. Disorders of the platelet and vessel wall. Harrison's principles of internal medicine. 16th ed. New York: McGraw Hill. 2005;673-74.

8. Frojmovic MM, Milton JG. Human platelet size, shape, and related functions in health and disease. Physiol Rev. 1982;62(1):185-261.

9. Chang HA, Hwang HS, Park HK, Chun MY, Sung JY. The role of mean platelet volume as a predicting factor of asymptomatic coronary artery disease. Korean J Fam Med. 2010;31(8):600-06.

10. Vagdatli E, Gounari E, Lazaridou E, Katsibourlia E, Tsikopoulou F, Labrianou I. Platelet distribution width: a simple, practical and specific marker of activation of coagulation. Hippokratia. 2010;14(1):28-32.

11. Yilmaz M, Delibas IB, Isaoglu U, Ingec M, Borekci B, Ulug P. Relationship between mean platelet volume and recurrent miscarriage: a preliminary study. Arch Med Sci. 2015;11:989-93.

12. Beckman JA, Creager MA, Libby P. Diabetes and atherosclerosis: epidemiology, pathophysiology, and management. J Am Med Assoc. 2002;287(19):2570-81.

13. Demirtunc R, Duman D, Basar M, Bilgi M, Teomete M, Garip T. The relationship between glycemic control and platelet activity in type 2 diabetes mellitus. J Diabetes Complications. 2009;23:89-94.

14. Winocour PD, Watala C, KinloughRathbone RL. Membrane fluidity is related to the extent of glycation of proteins, but not to alterations in the cholesterol to phospholipid molar ratio in isolated platelet membranes from diabetic and control subjects. Thromb Haemost. 1992;67:567-71.

15. Westerbacka J, Yki-Järvinen H, Turpeinen A, Rissanen A, Vehkavaara S, [16]Syrja lä $\mathrm{M}$, et al. Inhibition of plateletcollagen interaction: an in vivo action of insulin abolished by insulin resistance in obesity. Arterioscler Thromb Vasc Biol. 2002;22:167-172.

16. Handin RI, Karabin R, Boxer GJ. Enhancement of platelet function by superoxide anion. J Clin Invest.1977; 59:959-65.

17. Martin JF. Platelet heterogeneity in vascular disease. Martin JF, Towbridge A, eds. Platelet heterogeneity: Biology and Pathology. London, UK. Springer-Verlag. 1990;205:26.

18. Hekimsoy Z, Payzinb B, Ornek T, Kandogan G. Mean platelet volume in 
type 2 diabetic patients. J Diabetes Complications. 2004;18:173-76.

19. Bae SH, Lee J, Roh KH, Kim J. Platelet activation in patients with diabetic retinopathy. Korean J Ophthalmol. 2003;17:140-44. 